Tropical Journal of Pharmaceutical Research November 2021; 20 (11): 2347-2353

ISSN: $1596-5996$ (print); 1596-9827 (electronic)

(C) Pharmacotherapy Group, Faculty of Pharmacy, University of Benin, Benin City, 300001 Nigeria

\title{
Comparing efficacy and safety of plasmapheresis versus atorvastatin in pathological progression of atherosclerosis in a rodent model
}

\author{
Jun Zhang, Huawei Tian, Yuping Li* \\ Department of Cardiology, Xiangyang No. 1 People's Hospital, Hubei University of Medcine, Xiangyang, Hubei 441000, China
}

*For correspondence: Email: yuping.lih@gmail.com; Tel/Fax: 0086-0710-3420031

Sent for review: 2 April 2021

Revised accepted: 13 October 2021

\begin{abstract}
Purpose: To evaluate the effect of plasmapheresis versus atorvastatin in pathological progression of atherosclerosis in a rodent model.

Method: A total of 90 male adult rats of up to $300 \mathrm{~g}$ were randomly distributed in three groups $(n=30)$ : group 1 (plasmapheresis up to $1.5 \mathrm{ml}$ daily); group 2 (atorvastatin $0.1 \mathrm{mg} / \mathrm{kg}$ per day), and group 3 (hypercholesteremic rats). The following variables were assessed for 24 weeks: plasma and hepatic lipid and anti-oxidant profiles; atherosclerotic abrasions/lesions; coronary atherosclerosis/coronary stenosis score (CSS), composition of atherosclerotic lesions, incidence of xanthoma, arch and thoracic surface involvement including arch and thoracic area occupied by lesion; and thoracic aorta (I/M) ratio. Results: Compared to rats administered with atorvastatin, the rats treated with plasmapheresis had significantly greater improvement in levels of triglycerides (132 vs $124 \mathrm{mg} / \mathrm{dl}, p<0.05)$, total cholesterol (201 vs $189 \mathrm{mg} / \mathrm{dl}, p<0.05)$ ), low-density lipoproteins (134 vs $123 \mathrm{mg} / \mathrm{dl}, p<0.05)$ ), very-low-density lipoprotein (11 vs $9 \mathrm{mg} / \mathrm{dl}, p<0.05)$ ) and high-density lipoprotein (36 vs $39 \mathrm{mg} / \mathrm{dl}, p<0.05$ ) levels. Plasmapheresis after 24 weeks of treatment improve CSS in all coronary arteries than atorvastatin (22 vs 24 respectively; $p<0.05$. Furthermore, lesioned composition, I/M ratio and xanthoma incidence were significantly lower in plasmapheresis group than in atorvastatin group $(p<0.05)$.

Conclusion: Plasmapheresis is a better alternative than atorvastatin in preventing pathological progression of atherosclerosis.
\end{abstract}

Keywords: Atherosclerosis, Plasmapheresis, HMG-CoA reductase inhibitor, Atorvastatin, High cholesterol diet-induced atherosclerosis

This is an Open Access article that uses a funding model which does not charge readers or their institutions for access and distributed under the terms of the Creative Commons Attribution License (http://creativecommons.org/licenses/by/4.0) and the Budapest Open Access Initiative (http://www.budapestopenaccessinitiative.org/read), which permit unrestricted use, distribution, and reproduction in any medium, provided the original work is properly credited.

Tropical Journal of Pharmaceutical Research is indexed by Science Citation Index (SciSearch), Scopus, International Pharmaceutical Abstract, Chemical Abstracts, Embase, Index Copernicus, EBSCO, African Index Medicus, JournalSeek, Journal Citation Reports/Science Edition, Directory of Open Access Journals (DOAJ), African Journal Online, Bioline International, Open-J-Gate and Pharmacy Abstracts

\section{INTRODUCTION}

Atherosclerosis is a one of most common metabolic condition characterized by high level of cholesterol, triglyceride, LDL, VLDL and low level of $\mathrm{HDL}$, accounted for financial burden to patient and their family. In most case, the main cause of atherosclerosis is sedentary life style [1-3]. In severe cases of atherosclerosis, increased level of LDL (oxidized form) develop lesion in intima of coronary artery, and gradually form an atheromatic plaque which causes narrowing of coronary artery, that results in angina pectoris. Untreated serious conditions may lead to 
myocardial infraction which is the most common cause of death. Angina pectoris is the key characteristics of acute cardiac attack and one of the main reasons for the hospitalization [3-6].

Currently, statin group of drugs are being widely used to manage dyslipidemia and related disorders such as atherosclerosis, hypertriglyceridemia, hypercholesteremia [4-8]. The statin drug targets the rate limiting step of cholesterol synthesis by inhibiting key enzyme which is mainly involved in cholesterol synthesis. Higher levels of LDL are known to cause damage coronary artery by blocking adequate blood supply to coronary tissues. Role of cholesterol in developing coronary artery disease has been well established. Thus, reducing the level of cholesterol within the normal range is advisable as recommended by treatment guidelines. Safety of drugs used to control lipid levels, especially TG and LDL are also equally important. Although statin group of drugs are the standard treatment option, however, exerting serious adverse events after long term use. The most common adverse events of statin drugs are hepatic and renal damage. Thus, there is an unmet need of better treatment alternative in preventing pathological progression of atherosclerosis.

There were few reports showing efficacy of plasmapheresis in controlling blood lipid [9-12]. However, there is no study comparing safety and effectiveness of statin drugs and lipid removal using plasmapheresis or apheresis technique established. Since there is no comparative data available on effect of plasmapheresis versus HMG-CoA reductase inhibitor in high cholesterol diet-induced atherosclerosis. Therefore, this study designed to evaluate the effect of plasmapheresis versus atorvastatin in pathological progression of atherosclerosis in a rodent model.

\section{EXPERIMENTAL}

A total of 90 male adult rats of upto $300 \mathrm{~g} \mathrm{(} \mathrm{n}=30$ in each group) were divided three groups: group 1 (plasmapheresis up to $1.5 \mathrm{~mL}$ daily); group 2 (atorvastatin $0.1 \mathrm{mg} / \mathrm{kg}$ per day), and group 3 (hypercholesteremic rats). Diet containing cholesterol $(0.5 \%)$ and taurocholate $(1.0 \%)$, carbohydrates (55\%), fat (5\%), protein (25\%), and mineral $(10 \%)$ was administered to each group to induce hypercholesteremia. All the rats were placed in a separate cage in day and night cycle (12 $\mathrm{h}$ duration for each), with access of water as and when required. The study was approved by animal ethic committee board of Hubei University [approval number: HU/AECB-
2020/12-8/234] and followed the local regulation in conducting this experiment.

Body weight and feed intake of each rat were recorded every $3^{\text {rd }}$ day during the 24 weeks of study period. After 24 weeks of treatment, all rats were sacrificed using cervical dislocation and blood sample was collected using cardiac puncture to measure blood lipid profile using ELSIA kit. Thoracic aortae were used for histological examination using RT-PCR and ELSIA kit. Histological examination includes measurements of atherosclerotic abrasions/ lesions including superoxide anion $\left(\mathrm{O}^{2-}\right)$ and eNOS mRNA. Plasma sample were centrifuged and liver sample was also excised. Plasma sample, aortae/heart tissue and liver were frozen $\left(-80^{\circ} \mathrm{C}\right)$ until analysis. Also, antioxidant enzyme of cardiac tissue was assessed using ELSIA kit. Total liver cholesterol and liver triglyceride were measured. Moreover, atherosclerosis of the thoracic aorta of rats was used to assess coronary atherosclerosis/coronary stenosis and compared between both the treatment group. Furthermore, the area of lesioned components such as collagen, SMCs (smooth muscle cells), macrophage, lipid deposits for aortic and coronary lesion was compared between both the groups. Moreover, xanthoma was compared between both the groups as measured using Forelegs, incidence of Hind legs including severity of xanthoma was also assessed. Atheroma area was also assessed and compared. Also, arch and thoracic surface involvement including arch and thoracic area occupied by lesion and intima/media (I/M) ratio of arch and thoracic aorta was assessed between both the group.

Since this is pre-clinical study and designed to designed to compare the effect of plasmapheresis versus HMG-CoA reductase inhibitor in preventing the progression of atherosclerosis in high cholesterol diet-induced atherosclerosis in rat model. Therefore, no formal calculation of sample size performed as the present study is kind of pilot investigation to know whether plasmapheresis is effective and safe in preventing the atherosclerosis and atherosclerosis induced damage to coronary tissue.

\section{Statistical analysis}

Data were analyzed using appropriate statistical tests. Numerical data with normal distribution were analyzed using unpair $t$ test or Mann Whitney test based on the results of normality test. Categorical data were analyzed using chisquare test or fisher exact test based on the size 
of data in each cell. Statistical analysis of data was performed using SPSS statistical analysis software (version 26.0).

\section{RESULTS}

\section{Plasma lipid profile}

At baseline, lipid profile (triglyceride, total cholesterol, LDL and VLDL levels) was found comparable between both the groups. Biochemical analysis of plasma samples showed significant reduction in triglycerides, cholesterol (total), LDL and VLDL levels from baseline after 24 weeks of treatment of plasmapheresis. A similar trend of decreased triglycerides, cholesterol (total), LDL and VLDL levels were observed from baseline after 24 weeks of treatment of atorvastatin. On between group comparison, it was observed that the rats treated with plasmapheresis had significantly greater reduction in levels of triglyceride, cholesterol (total), LDL and VLDL as compared to atorvastatin after 24 weeks of treatment. Plasma samples showed that significant improvements in HDL levels from baseline after 24 weeks of treatment of plasmapheresis. Similar trend of improvements in HDL levels was observed from baseline after 24 weeks of treatment of atorvastatin. On between group comparison, it was observed that the rats treated with plasmapheresis had significantly greater improvement in levels of HDL as compared to atorvastatin after 24 weeks of treatment (Figure 1).

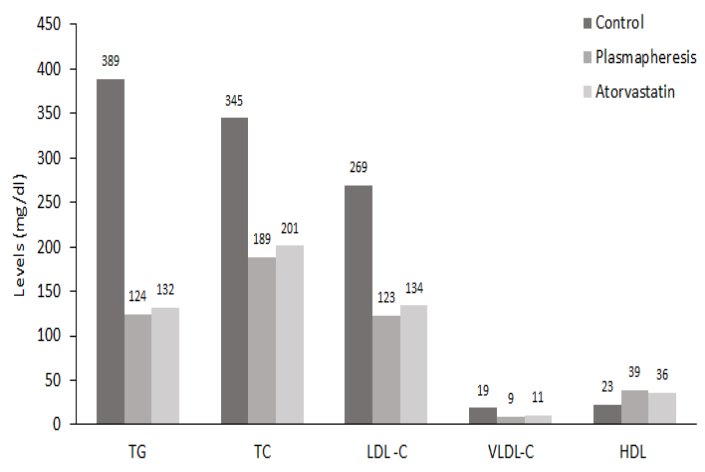

Figure 1: Plasma lipid levels in rats of all groups

\section{Liver lipid profile}

Further, it was observed that the rats treated with plasmapheresis had significantly greater improvement in liver lipid levels when compared to atorvastatin after 24 weeks of treatment (Figure 2).

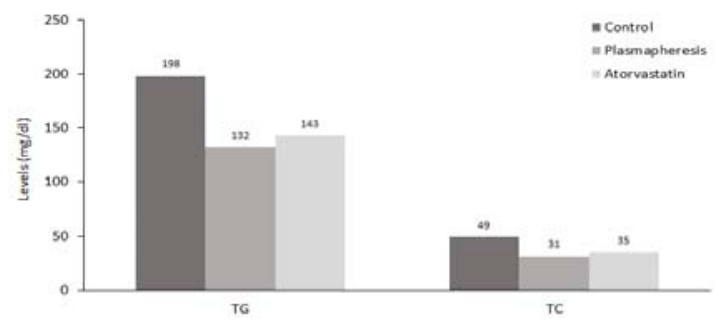

Figure 2: Liver lipid levels in rats of all groups

\section{Plasma levels of antioxidant enzymes}

Antioxidant analysis of cardiac tissue showed that there was no statistically significant difference in plasma levels of antioxidant enzymes, however, plasmapheresis after 24 weeks of treatment showed marginal improvement of anti-oxidant status when compared to rats treated with atorvastatin (Table 1).

\section{Hepatic levels of antioxidant enzymes}

The level of antioxidant enzymes (catalase and SOD) were significantly improved from baseline after weeks of treatment of plasmapheresis and atorvastatin. However, between group comparison showed that there is no statistically significant in improving the levels of SOD and catalase, although plasmapheresis treatment numerically improves the level of anti-oxidant enzymes. Similar trend of results was observed for levels of ascorbic acid, both the treatments showed significant improvement from baseline after 24 weeks of treatment, however, there was no statistically significant difference exists when compared plasmapheresis and ascorbic acid, although the plasmapheresis treated rats had numerical improvement in level of ascorbic acid when compared to ascorbic acid.

Table 1: Plasma levels of antioxidant enzymes in rats

\begin{tabular}{lccc}
\hline Antioxidant enzyme & $\begin{array}{c}\text { Control } \\
(\mathbf{n = 3 0 )}\end{array}$ & $\begin{array}{c}\text { Plasmapheresis } \\
(\mathbf{n}=\mathbf{3 0})\end{array}$ & $\begin{array}{c}\text { Atorvastatin } \\
(\mathbf{n}=\mathbf{3 0})\end{array}$ \\
\hline $\begin{array}{l}\text { Catalase }\left(\mathrm{nmH}_{2} \mathrm{O}_{2} \text { decomposed (per s/g, }\right. \\
\text { mean, } \mathrm{SD})\end{array}$ & $12(7.1)$ & $32(4.2)^{\star \#}$ & $30(3.3)^{\star \#}$ \\
$\mathrm{SOD}(\mathrm{U} / \mathrm{mg}$ protein), mean $(\mathrm{SD})$ & $4.4(1.1)$ & $8.3(2.1)^{\star \#}$ & $7.5(2.2)^{\star \#}$ \\
Ascorbic acid (ug/g), mean (SD) & $121(21.2)$ & $189(12.4)^{\star \#}$ & $184(13.2)^{\star \#}$ \\
\hline$P<0.05$ compared to control; \# $\mathrm{P}>0.05$ compared to plasmapheresis/atorvastatin &
\end{tabular}


Table 2: Liver level of antioxidant enzymes in rats ps

\begin{tabular}{lccc}
\hline Antioxidant enzyme & Control $(\mathbf{n}=\mathbf{3 0})$ & Plasmapheresis $(\mathbf{n}=\mathbf{3 0})$ & Atorvastatin $(\mathbf{n}=\mathbf{3 0})$ \\
\hline Catalase $\left(\mathrm{nmH}_{2} \mathrm{O}_{2}\right.$ decomposed & $12(7.1)$ & $32(4.2)^{\star \#}$ & $30(3.3)^{\star \#}$ \\
per $\mathrm{Sec}$ per g, mean (SD) & & & \\
SOD $(\mathrm{U} / \mathrm{mg}$ protein), mean (SD) & $4.4(1.1)$ & $8.3(2.1)^{\star \#}$ & $7.5(2.2)^{\star \#}$ \\
Ascorbic acid (micrograms per & $121(21.2)$ & $189(12.4)^{\star \#}$ & $184(13.2)^{\star \#}$ \\
gram), mean (SD) & & \\
${ }^{*} P<0.05$ compared to control; ${ }^{\#} p>0.05$ compared to plasmapheresis/ atorvastatin &
\end{tabular}

Similar trend of result was observed for liver tissue for which antioxidant analysis was performed (Table 2).

Overall, plasmapheresis and atorvastatin significantly improved the level of anti-oxidant enzyme as compared to hypercholesteremic rats.

\section{Coronary stenosis score of coronary arteries}

Coronary atherosclerosis was measured using coronary stenosis score (CSS) for all the coronary arteries namely left coronary main artery (LMT), right coronary artery (RCA), left circumflex artery (LCX), and start of right artery (RCO). The CSS in each coronary artery was measured and compared between both the group. The analysis results showed that there was no statistically significant difference between both treatments, however, treatment with plasmapheresis showed marginal improvement in CSS for all coronary arteries namely LMT, RCA, LCX and RCO when compared to rats treated with atorvastatin (figure 3). Overall, plasmapheresis and atorvastatin significantly reduce the coronary stenosis score as compared to hypercholesteremic rats.

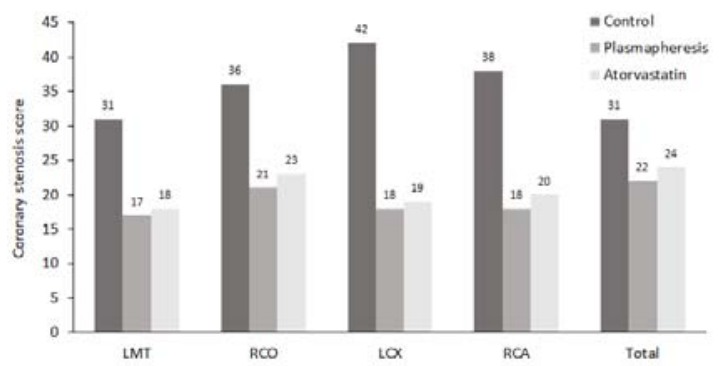

Figure 3: Coronary stenosis score of coronary arteries in rats of all groups

\section{Lesioned composition of aortic and coronary atherosclerosis}

Compared to control group, rats treated with plasmapheresis and atorvastatin had significantly lower \% of lesioned composition such as collagen, smooth muscle cell, macrophage, and lipid deposits (Figure 4). However, reduction in \% of lesioned composition was significantly higher in rats treated with plasmapheresis compared with atorvastatin (Figure 4). This indicated that plasmapheresis is effective in preventing the progression of atherosclerosis in high cholesterol diet-induced atherosclerosis.

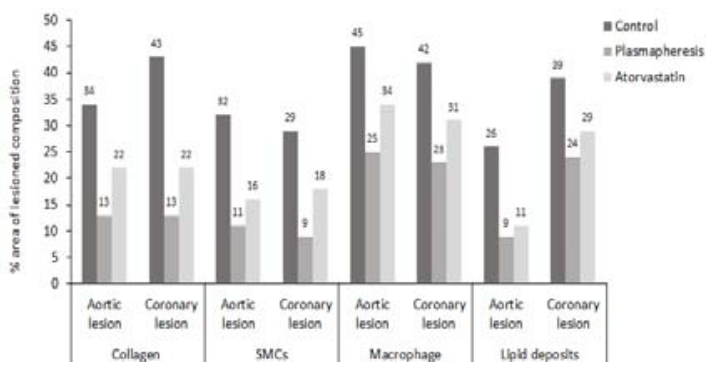

Figure 4: Lesioned composition of aortic and coronary atherosclerosis in rats of all groups

\section{Histological features of atherosclerotic area}

Compared to control group, rats treated with plasmapheresis and atorvastatin had significantly lower arch and thoracic surface involvement including lesion area and I/M ratio (Figure 4). However, \% lesion was significantly higher in rats treated with plasmapheresis compared with atorvastatin (Figure 4).

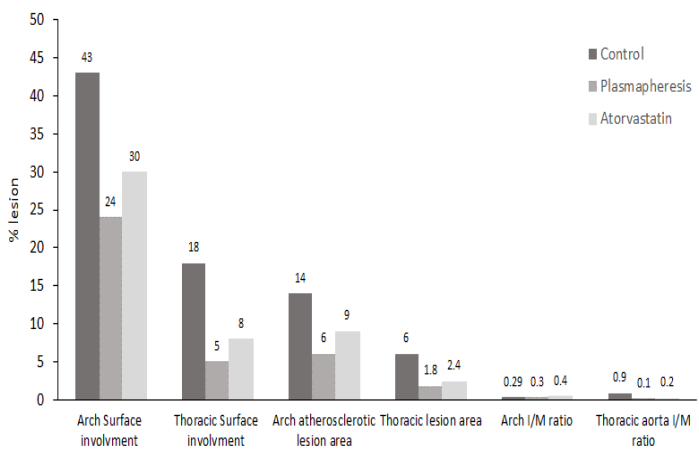

Figure 5: Histological assessment of atherosclerotic area in rats of all groups

\section{Xanthoma}

On comparing plasmapheresis vs atorvastatin, 
Table 3: Comparison of xanthoma in rats of all groups

\begin{tabular}{|c|c|c|c|c|c|c|c|}
\hline \multirow[t]{2}{*}{ Group } & \multirow[t]{2}{*}{ Forelegs } & \multirow{2}{*}{$\begin{array}{c}\text { Hind legs } \\
\text { (incidence, \%) }\end{array}$} & \multirow[t]{2}{*}{ Total } & \multicolumn{4}{|c|}{ Severity of xanthoma (\%), distribution } \\
\hline & & & & - & + & ++ & +++ \\
\hline Control & 100 & 100 & 100 & 0 & 59 & 57 & 13 \\
\hline Plasmapheresis & 100 & 62 & 55 & 18 & 12 & 9 & 0 \\
\hline Atorvastatin & 100 & 75 & 65 & 17 & 15 & 13 & 0 \\
\hline
\end{tabular}

plasmapheresis treated rats had significantly lower incidence of xanthoma when compared to the rats treated with atorvastatin (Table 3 ).

\section{DISCUSSION}

This is first pre-clinical study designed to evaluate the effect of plasmapheresis versus atorvastatin in pathological progression of atherosclerosis in a rodent model. Also, compared the efficacy and safety of plasmapheresis with atorvastatin. The results of this study will serve the basis of future clinical investigation and may give a new alternative option to scientific community and researcher to think on therapy based on plasmapheresis in management of atherosclerosis and atherosclerosis induced coronary complications. It has been reported in various epidemiological studies that lipid lower drugs that effectively reduces the plasma and liver lipid levels are significantly reduces the cardiac related morbidity and mortality [13-16]. This finding of epidemiological studies was consistent with the present study, in which it was observed that the rats treated with plasmapheresis had significantly greater improvement in levels of triglycerides, total cholesterol, low-density lipoproteins, verylow-density lipoprotein and high-density lipoprotein levels. Moreover, plasmapheresis after 24 weeks of treatment significantly improved CSS in all coronary arteries than atorvastatin $(p<0.05)$. Furthermore, lesioned composition, I/M ratio and xanthoma incidence were significantly lower in plasmapheresis group than atorvastatin ( $p<0.05$ for each comparison). The results of present study pertaining to statin group were consistent with published study, where statin group of medicine was found effective in reducing lipid levels [17-20]. Moreover, the effect of plasmapheresis in reducing the lipid level such as cholesterol, and triglyceride was consistent with the previous reports [21]. Since there is no study comparing safety and effectiveness of statin drugs versus lipid removal using plasmapheresis or apheresis technique established. This study showed that plasmapheresis demonstrate significantly greater reduction plasma and liver lipid levels as compared to atorvastatin.
In the present study, histological assessment was performed to understand whether statin and plasmapheresis are effective in preventing the progression of coronary artery diseases. In the present study, plasmapheresis and atorvastatin significantly reduce the coronary stenosis score when compared to hypercholesteremic rats. The analysis results showed that plasmapheresis after 24 weeks of treatment marginally improve CSS in all coronary arteries when compared to rats treated with atorvastatin. This possibly due to antioxidant effect of plasmapheresis where improvement in level of anti-oxidant was slightly greater in rat treated with plasmapheresis when compared to statin. Similar trend of results was observed for coronary lesion (for percentage of area of lesioned composition), where hypercholesteremic rats had significantly higher $\%$ of lesioned composition when compared to rats treated with plasmapheresis and atorvastatin. On comparing plasmapheresis vs atorvastatin, plasmapheresis treated rats had significantly higher percentage of lesioned composition when compared to rats treated with atorvastatin. Moreover, compared to hypercholesteremic rats, rats treated with plasmapheresis and atorvastatin had significantly lower arch and thoracic surface involvement including lesion area and I/M ratio.

Overall, the results of the present study showed that plasmapheresis is found effective in preventing the progression of atherosclerosis in high cholesterol diet-induced atherosclerosis, in fact better than atorvastatin. This indicates that plasmapheresis could be as effective as atorvastatin and can be considered as better alternative in management of atherosclerosis and atherosclerosis induced long term complications such as coronary artery disease. The results of this study recommended the use of plasmapheresis as a better alternative in the management of atherosclerosis. However, pilot clinical study followed by large clinical study with adequate sample size to be conducted to provide recommendation for clinical use. The results of this study will serve the basis of future clinical investigation and may give a new option to scientific community and research to think on therapy based on plasmapheresis in 
management of atherosclerosis and atherosclerosis induced coronary complications.

\section{Limitations of the study}

The findings of the present trial cannot to be generalized to the Chinese population since the study was conducted at a single study centre in China. A large clinical trial with an appropriate sample size is needed to confirm the present findings.

\section{CONCLUSION}

Plasmapheresis may be considered a better alternative in the management of atherosclerosis as it is effective in preventing pathological progression of atherosclerosis-induced long-term complications such as coronary artery disease.

\section{DECLARATIONS}

\section{Conflict of Interest}

No conflict of interest associated with this work.

\section{Contribution of Authors}

The authors declare that this work was done by the authors named in this article and all liabilities pertaining to claims relating to the content of this article will be borne by them.

\section{Open Access}

This is an Open Access article that uses a funding model which does not charge readers or their institutions for access and distributed under the terms of the Creative Commons Attribution License (http://creativecommons.org/licenses/by/ 4.0) and the Budapest Open Access Initiative (http://www.budapestopenaccessinitiative.org/rea d), which permit unrestricted use, distribution, and reproduction in any medium, provided the original work is properly credited.

\section{REFERENCES}

1. Ross R. Atherosclerosis - an inflammatory disease. $N$ Engl J Med 1999; 340: 115-126.

2. Steinberg D. Low density lipoprotein oxidation and its pathological significance. J Biol Chem 1997; 272: 20963-20966.

3. Tiwari AK. Natural product antioxidants and their therapeutic potential in mitigating peroxidative modification of lipoproteins and atherosclerosis: recent development. J Med Arom Plant Sci 1999; 21: 730-741.
4. Lindequist $U$, Niedermeyer THJ, Julich WD. The pharmacological potential of mushrooms. Evid Based Complement Alternat Med 2005; 2: 285-299.

5. Venkatesan $N$, Devaraj SN, Devaraj H. Increased binding of $L D L$ and VLDL to apo $B, E$, receptors of hepatic plasma membrane of rats treated with fibernat. Eur $\mathrm{J}$ Nutr 2003; 42: 262-271.

6. Ikeda I, Sugano M. inhibition of cholesterol absorption by plant sterols for mass intervention. Curr Opin Lipidol 1998; 9: 527-531.

7. Harwood HJ Jr, Chandler CE, Pellarin LD, Bangerter FW, Wilkins RW, Long CA, Cosgrove PG, Malinow MR, Marzetta CA, Pettini JL. Pharmacologic consequences of cholesterol absorption inhibition: alteration in cholesterol metabolism and reduction in plasma cholesterol concentration induced by the synthetic saponin b-tigogenin cellobioside (CP-88818; tiqueside). J Lipid Res 1993; 34: 377-395.

8. Friedewald WT, Levy RT, Fredrickson DS. Estimation of the concentration of low-density lipoprotein cholesterol in plasma without use of the preparative ultracentrifuge. Clin Chem 1972; 18: 499-502.

9. Folch J, Lees M, Sloane Stanley GH. A simple method for the isolation and purification of total lipids from animal tissues. J Biol Chem 1957; 226: 497-509.

10. Ahmed TC, Bilal M, Guturu P. Evaluation and management of acute pancreatitis. World J Clin Cases 2019; 7(9): 1006-1020.

11. Aida H. Inflammation in Acute and Chronic Pancreatitis. Curr Opin Gastroenterol 2015; 31(5): 395-399.

12. Nojgaard C, Becker U, Matzen P, Andersen JR, Holst C, Bendtsen F. Progression from acute to chronic pancreatitis: prognostic factors, mortality, and natural course. Pancreas 2011; 40:1195-1200.

13. Shepherd J, Cobbe SM, Ford. Prevention of coronary heart disease with pravastatin in men with hypercholesterolemia. N Eng J Med 1995;333:13011307

14. Scandinavian Simvastatin Study Group. Randomized trial of cholesterol lowering therapy in 4444 patients with coronary heart dease: the Scandinavian Simvastatin Survival Study (4S). Lancet 1994; 344:1383-1389.

15. Downs JR, Clearfield $M$, Weis $S$. For the AFCAPS/TexCAPS Research Group. Primary prevention of acute coronary events with lovastatin in men and women with average cholesterol levels: results of AFCAPS/TexCAPS. JAMA 1998; 279: 1615-1622

16. The Long-Term Intervention with Pravastatin in Ischemic Disease (LIPID) Study Group. Prevention of cardiovascular events and death with pravastatin in patients with coronary heart disease and a broad range of initial cholesterol levels. N Engl J Med 1998; 339: 1349-1357.

17. Cho JH, Lee NJ, Chai HY, Kim TM, Park JH, Kang JK, Kim YB, Hwang SY. Effect of Hwalgidan SJ-101 on atherosclerosis in hypercholesterolemic rabbits. Lab Anim Res 2005; 21: 149-158.

Trop J Pharm Res, November 2021; 20(11): 2352 
18. Hong SH, Chai HY, Kim TM, Lee NJ, Kim DK, Cho JH, Park JH, Kim YB, Kang JK, Hwang SY. Therapeutic effects of mulberry root-bark (Mori radicis Cortex) ethanol-extracts on atherosclerosis in hypercholesterolemic rabbits. Lab Anim Res 2005; 21 : 273-279.

19. Jung DS, Porzel A, Huneck S. Gigasol and other coumarins isolated from Angelica gigas. Phytochemistry 1991; 30: 710-712.21.

20. Hayashi T, Arockia RP, Fukatsu A, Matsui-Hirai $H$, Osawa M, Miyazaki A, Tsunekawa T, Kano-Hayashi $H$,
Iguchi $A$, Sumi $D$, Ignarro LJ. A new HMG-CoA reductase inhibitor, pitavastatin remarkably retards the progression of high cholesterol induced atherosclerosis in rabbits Toshio Hayashi. Atherosclerosis 2004;176(2):255-263.

21. Kumai T, Oonuma S, Matsumoto N, Takeba $Y$, Taniguchi R, Kamio K, Miyazu O, Koitabashi Y, Sekine S, Tadokoro M, Kobayashi S. Anti-lipid deposition effect of HMG-CoA reductase inhibitor, pitavastatin, in a rat model of hypertension and hypercholesterolemia. Life Sci 2004; 74(17): 2129-2142. 